\title{
Interaction of the Causal Agent of Apricot bud gall Acalitus phloeocoptes (Nalepa) with Apricot: Implications in Infested Tissues
}

Shijuan Li1, Muhammad Khurshid2, Junsheng Yao3, Mohammed Mujitaba Dawuda4, Jin Zhang5,

Zeeshan Hassan6, Shahbaz Ahmad7, Bingliang Xu 1†

1 Shijuan Li, College of Plant Protection, Gansu Agricultural University, Lanzhou 730070, China;

$1 \uparrow$ Bingliang Xu, College of Plant Protection, Gansu Agricultural University, Lanzhou 730070, China;

2 Muhammad Khurshid, School of Biochemistry and Biotechnology, University of the Punjab, Lahore 54500, Pakistan;

3 Junsheng Yao, Gansu agriculture vocational and technical college, Horticulture technology;

4 Mohammed Mujitaba Dawuda, College of Horticulture, Gansu Agricultural University, Yingmen Village, Anning District, Lanzhou, Gansu 730070, China; Department of Horticulture, FoA, University for Development Studies, P. O. Box TL 1882, Tamale, Ghana;

5 Jin Zhang, College of Pastoral Agriculture Science and Technology, Lanzhou University, Lanzhou 730020, Gansu, China;

6 Zeeshan Hassan, College of Agriculture, Bahauddin Zakariya University, Bahadur Sub Campus Layyah, Multan 31200, Pakistan;

7 Shahbaz Ahmad, institute of agricultural sciences, University of the Punjab, Lahore 54500, Pakistan.

$\uparrow$ Corresponding author: Bingliang Xu;

E-mails: xubl@gsau.edu.cn; 1153657458@qq.com.

\begin{abstract}
Apricot bud gall mite, Acalitus phloeocoptes (Nalepa), is a destructive arthropod pest that causes significant economic losses to apricot trees worldwide. Infested bud examination revealed that the starch granules in the bud axon were extended at the onset of the attack. During the later stages of the attack, the cytoplasm was distributed in apricot. The results also demonstrated that the accumulation of large amounts of cytokinin (zeatin, ZT) and auxin (indoleacetic acid, IAA) led to rapid bud proliferation during the rapid growth period. Abscisic acid (ABA) controls the development of gall buds and plays a vital role in gall bud maturity. The reduction of gibberellic acid (GA3) content led to rapid lignification at the later phase of bud development. Our results reveal the mechanism underlying
\end{abstract}


the interaction of apricot bud gall with its parasite and provide reliable information for designing valuable breeding programs. This study will be quite useful for pest management and will provide a comprehensive evaluation of ecology-based cost-effective control, life history and demographic parameters of $A$. phloeocoptes.

\section{INTRODUCTION}

Apricot bud gall mite, A. phloeocoptes (Nalepa), is one of the most destructive pests found in apricot-producing regions worldwide, including central and southern Europe, the Mediterranean areas, North and South America, and East Asia [1]. This pest was first reported in 1890 by Nalepa [2] as plum pest. The occurrence of apricot bud gall mites in China was reported in 1991[3]. Later, the pest was identified as A. phloeocoptes by Kuang [4]. Apricot bud gall is characterized by malformation of apricot buds grown in various sizes, causing severe yield loss [5]. In recent years, the infestation of apricots by the apricot bud gall mites had become a significant threat to the development of the apricot industry in northwest China [6].

The fundamental challenge of pest management is to understand the life cycle of mite concerning time and space. Till now, little is known about the mite's life cycle and outbreak. A. phloeocoptes is a specie of Eriophyoidea, which is considered as the most diverse group of phytophagous mites [7], and are economically important pests [8]. They can disrupt the growth and physiology of host plants [9-11]. Population increase can be predicted by understanding mite's biological characteristics (egg, nymph, and adult).

Understanding the mode of dispersal is vital for managing populations of eriophyoid mites. Currently, only $2.5 \%$ of the approximately 4000 known eriophyoid mite transmission routes have been recorded [12-13]. Eriophyoid mites have limited capacity in ambulatory movement because of the tiny body [14], the ability to disperse over long distances [15], or by airflow from the surface of the hosts [16]. An accurate understanding of the ultrastructure of infested apricot bud gall is essential for assessing the degree of damage to invaded apricot trees. Lanjinghua, reported the ultrastructural changes in cotton leaves affected by Carmine spider mite and showed that the disintegrated organelles and incomplete chloroplast membrane. Significant changes were also observed in the ultrastructure of cells in the mulberry leaves, attacked by Eotetranychus suginamensis [17].

It is suggested that phytohormones secreted by insects play a major role in gall formation and development [18]. The mechanism underlying the generation of insect gall was studied for a long time but remains largely unknown. The activity in various levels of the auxin indole-3-acetic acid (IAA) has been demonstrated in extracts of gall-forming homopterans [18]. The characteristic pattern of cell division and vascular-tissue development in galls of many insects points that the insect was the source of phytohormones in galls [19]. Recently it was suggested that auxin (IAA), cytokinin (CK), abscisic acid (ABA) and gibberellic acid (GA3) play a vital role in the induction and development of plant galls when infected by insects [20-22]. In view of the above, we tested the hypothesized phytohormones mostly related to the development of galls.

The occurrence and spread of gall mite depend on abiotic factors and the resistance of the host plants [23-24]. Therefore, molecular methods are now being used to asses resistance. Investigation of different apricot cultivars for A. phloeocoptes infestation and identification of resistant cultivar and mechanism of resistance will help improve the disease management. Here, we studied the mode of dispersal of A.phloeocoptes, the development and ultrastructure of Apricot bud gall, and the role of phytohormones in the formation of the apricot bud galls. All of the 
results were center on the interaction between apricot bud gall with their parasite. Wetried to find reliable information for valuable varieties useful for future breeding for A. phloeocoptes management.

\section{MATERIALS AND METHODS}

\section{Field Investigation and Identification of Apricot Bud Gall Mite}

Field evaluation of apricot bud gall mites was carried out in three consecutive years in eight year old apricot orchards located in a popular apricot-producing area Qinwangchuan District, Lanzhou City, China. The prevailing wind direction was north-west. Twenty apricot orchards in the area were selected for the study in a "Z" pattern. Five sites per apricot orchard were sampled, and each sample consisted of six arbitrarily selected trees. Therefore 30 apricot trees were sampled in each orchard. Ten branches were analyzed in each location (east, south, west, north, and center) per sampled tree. Each branch was observed according to the classification (Supplementary Table 1). The pest infestation index was calculated based on the following formula:

$P$ est infestation index $=\frac{\left.\sum_{k=0}^{4} \text { (the number of branches } \times \text { quantitative value of the grade }\right)}{\text { the total number of branches } \times \text { the heaviest representative value }} \times 100$

Where $k$ is the $k$ th quantitative value, and 4 is the number of all quantitative levels; the branch number represents the number of quantitative levels.

The morphological features of apricot bud gall mites were carefully observed using a Hitachi S-3400 scanning electron microscope and stereo microscope in the laboratory. Morphological components of different insect stages, including adults, nymphs, and eggs, were picked with an entomological needle under the stereomicroscope and then studied using the electron microscope to determine the sample stage. Different parts of the mites were measured and photographed.

\section{Life Cycle Studies}

To study the mite life cycle, overwintering locations, and mite stages, annual statistics of life stages were analyzed in several orchards in Qinwangchuan District during early March every year. Samples of gall, branches, bark cracks, and soil (up to 3-cm deep) around the mite-infested trees in the orchard were collected and put into separate plastic bags and taken to the laboratory for detailed observation under magnifying glass and stereo microscopes. Three galls were collected randomly from each branch, and the number of mites on ten young leaves per gall was recorded. The number of mites in different life stages was also calculated monthly.

To gain a better understanding of the mechanisms involved in A. phloeocoptes dispersal, a transparent adhesive tape method was used. Sampled branches close to galls were wrapped with $1 \mathrm{~cm}$ wide transparent adhesive tape (the adhesive side outwards). Similarly, the trunk at 1 meter above ground was wrapped with $10 \mathrm{~cm}$ wide transparent adhesive tapes. Wrapped tapes were removed from the branches and brought to the laboratory for detailed investigation after 10 days. Sampling was performed once every 10 days beginning from early March. Active 
transmission of eriophyes was determined by observing the sampled branches using an electron microscope. In early May, the potential spreading of eriophyes through insects, winds, rainfall, and farming practices were observed.

\section{Morphology of Infested Apricot Bud}

Morphological observation of infested apricot buds was carried out by paraffin sectioning [25], which is often used for anatomical analysis under light microscopy. Infested apricot bud gall and healthy apricot buds of 2-yearold branches were used for this analysis. Healthy and infested buds were cut equally in two and immersed in Formalin Acetic acid Alcohol fixative solution (FAA) in a timely manner [26]. Paraffin sectioning was performed by following different steps including fixation, washing, dehydration, wax immersion, embedding, sectioning, sticking slice, wax dissolving, dyeing, hydrating, and sealing with gum [27]. The tissue structure of infested apricot bud gall and healthy apricot buds were compared using light microscope [28]. To support the ultrastructure details, we measured buds parameters, including the width of bud axis and the parameters of immature leaves.

Infested bud ultrastructure was observed under transmission electron microscopy by ultrathin sectioning. Infested apricot bud gall and healthy apricot buds of 2-year-old branches were cut in half lengthwise and immersed in glutaraldehyde fixing solution. Ultrathin sectioning was performed through steps including fixation, rinsing, dehydration, saturation, embedding, resin polymerization, sectioning, and finally dying. Immature leaves and bud axes were observed [29-30].

\section{Quantification of phytohormones}

Infected and healthy plant materials were collected from naturally growing apricot trees in Qinwangchuan District, China. Materials were collected from the field monthly during the growing season (on 30th of each month from april to september). Field collections were necessary because of the large numbers of galls needed for our analyses. Overall, more than 100 galls were taken to obtain sufficient tissues for extraction. All samples were frozen in liquid nitrogen and stored at $-80^{\circ} \mathrm{C}$ until extraction. Samples $(0.5 \mathrm{~g}$ dry weight each $)$ were ground to a fine powder using mortars and extracted in $15 \mathrm{ml} 80 \%$ methanol which was precooled at $4^{\circ} \mathrm{C}$ for $12 \mathrm{~h}$. Then, centrifugation at $8000 \mathrm{rpm}$ for $10 \mathrm{~min}$ at $4^{\circ} \mathrm{C}$, remove the supernatant, add $5 \mathrm{ml}$ precooled $80 \%$ methanol and incubated for 3 hours. Centrifugation at $8000 \mathrm{rpm}$ for $10 \mathrm{~min}$ at $4^{\circ} \mathrm{C}$. Decompress and concentrate the supernatant from the above two steps to remove methanol at $40^{\circ} \mathrm{C}$, decolorize and extract in light petroleum for one time, discard petroleum phase, adjusted to $\mathrm{pH} 2.9$, stored at $4^{\circ} \mathrm{C}$. The whole experimental procedure were done under low light condition [31-32]. Phytohormones including gibberellin (GA), zeatin (ZT), indoleacetic acid (IAA) and abscisic acid (ABA) in the tissue samples were quantified by HPLC [33].

\section{Results}

\section{Field and laboratory studies on apricot bud galls}

\section{Observed Symptoms}

Apricot bud gall mites mainly attacked apricot buds, forming a typical bud gall. A gall consisted of numerous buds, which became brown with almost no sprouting or occasionally some weak buds sprouted and survived many 
years on the branch. The buds in the gall were loose, hyperplastic, brittle, could be easily broken with tweezers, and the internal scales on the buds were not covered by external scales. Gall diameters were 1-4 cm on the 1-2-year-old apricot branches with dense bud growth. However, 5-8-cm galls occurred on severely damaged apricot branches with more than 20 buds (Fig.1).

It was observed that the flowering of infested apricot trees was delayed, the foliage became deformed, and fewer fruits of poor quality were produced. Occasionally, the whole tree showed stunted growth, while some of the trees died (Fig. 1). We observed that apricot bud gall occurred more severely in densely planted orchards than those with wide spacing. Intensive orchard management reduced the chances of disease onset, which was in agreement with the previous report by $\mathrm{Wu}$ [34]. It was observed that Apricot bud galls were more prevalent on 2-3-year-old branches than older branches.

\section{Morphological Features of Apricot Bud Gall Mites}

Electron microscopic studies identified apricot bud gall mites as A. phloeocoptes. The adult female bodies are vermiform and ivory, $177.38-265.67 \mu \mathrm{m}$ long, and 44.11-60.59 $\mu \mathrm{m}$ wide. The anterior part of the body is slightly wider and carrot-shaped (Fig. 2A). The female genital is $16.780 .59 \mu \mathrm{m}$ wide. The ant.90-26.85 $\mu \mathrm{m}$ wide, and the genital cover has flap distributed grain (Fig. 2B). The feather claw has five lateral ramifications (Fig. 2D), with two pairs of legs and three pairs of coxal setae. The dorsal shield resembles an isosceles triangle, smooth and without anterior lobe, which is $20-25.6 \mu \mathrm{m}$ long and $34.68-40.60 \mu \mathrm{m}$ wide. The dorsal tubercle was located at the back edge of the dorsal shield (Fig. 2C). The body section is divided into three parts. The dorsal seta is $20 \mu \mathrm{m}$ long and projected backward diagonally. Tergites of the body is arched with 64 witring. The adult female is $48.26 \mu \mathrm{m}$ long and $33.63 \mu \mathrm{m}$ wide (Fig. 2E). The eggs are white and oval-shaped, approximately $48.26-53.31 \mu \mathrm{m}$ long and 33.63-40.12 $\mu \mathrm{m}$ wide (Fig. 2F). Male adults were not collected in the present experiment because they were not found.

Ultrathin sectioning of infested apricot buds under electron microscopy revealed additional ultrastructure details. The anatomical structures of the attacked apricot tree buds were different from those of healthy buds (Fig. 4). A healthy bud axis had only one bud, but an infested bud was deformed and had more than one bud. The bud primordium was covered by $1-3$ layers of lamellar structure during the initial stages of apricot bud gall formation. At the mid-stage, the bud primordium grew into a new bud while, at a later stage, a bud axis branched out to form approximately 4 - 5 bud axes, and each axis was covered by the layer of young leaves, an apricot bud gall was formed afterward (Fig. 4). Careful measurements of infested buds demonstrated that the width of the lower part of the bud axis was $1500.8 \mu \mathrm{m}$ whereas the healthy ones were $332.0 \mu \mathrm{m}$. Infested buds had more number of immature leaves than healthy buds, infested buds had 24 leaves however, healthy buds had 12 (Supplementary Table 3).

\section{The Regularity Outbreak of $A$. Phloeocoptes and Their Disperse Mode}

The life cycle study revealed that $A$. phloeocoptes mainly survived through winter in tight, live galls. Adults accounted for $70.4 \%$ of all mites, whereas nymphs and eggs accounted for $15.1 \%$ and $12.6 \%$, respectively; Mites were mostly found in galls. In branches and cracked bark, $0.6 \%$ of only adults were found. mites were not found in the surrounding soil. Therefore, these mites mainly survive over winter in tight, live galls as adults and a few eggs 
(Supplementary Table 2. Number of Acalitus phloeocoptes (Nalepa) in different stages. Measured from various overwintering places in three consecutive years in Lanzhou City, Gansu Province, China).

The number of mites at each life stage (egg, nymph, and adult) was counted under stereomicroscope. Oviposition peaked in May, with the highest value of 10.864 eggs; the number of nymphs was highest in June, with a maximum value of 27.361 nymphs; and the number of adults peaked in July, with the highest value of 61.362 adults. The number of adults decreased with the decrease in temperature during September (Table 1. Annual statistic of life stages.).

We observed that the passive dispersal modes of $A$. phloeocoptes include wind, animals and agricultural activities. Due to the tiny body, mites could be taken away by a strong wind from one tree to another or from one orchard to another. When observed under the microscope in the laboratory, the transparent adhesive tape wrapped on the trunk 1 meter above the ground captured more mites on the windward side, which indicated that wind was one of the passive dispersal modes of the mite. In addition, animal carries were another important dispersal mode. We also observed that the mites could attach themselves to other animals, such as ostracum of Pseudaulacaspis pentagona (Targioni Tozzetti) and Didesmococcus koreanus Borchsenius, which can be found around the apricot bud galls. A large number of scale insect nymphs could be found in apricot bud galls (Fig. 3), and many adults, nymphs, and eggs of $A$. phloeocoptes attached to the body of insects were found as well. Moreover, there were many nymphs of Chilocorus rubidus hosted on the back of apricot leaves, many eggs of $A$. phloeocoptes accreted with the body of these nymphs. Therefore, dispersal through insects would be more efficient than other dispersal modes, because insects could take them away from the current host. Furthermore, animal carries could increase the probability of attaching to a moving object, such as an insect, a larger mite or even a human. Therefore, animal carries could serve as a long-distance medium for passive dispersal. Farm practices were also the main transmission route, including farming operations and seedling and scion preparations.

\section{Ultra-Structural Changes of Infested Apricot Bud}

\section{Ultrastructure of Infested Bud}

Examination of the affected buds under transmission electron microscopy showed that during the early stage of infection, starch granules in bud axon were expanded and occupied a significant portion of chloroplast space as compared with those found in healthy buds (Fig. 5A-B). The cytoplasm seemed to be swollen and deformed. Many small vacuoles in the cell were distributed on the edges of the cell (Fig. 5C). In the later stages of infestation, the cytoplasm of each infected cell was wholly disrupted, with severely deformed chloroplasts, mitochondria and irregular vacuoles (Fig. 5D).

\section{Ultrastructure of Affected Bud Leaf}

The cell wall of apricot bud leaf in infested cells was thicker (Supplementary Fig. 1B) than those in healthy cells (Supplementary Fig. 1A). The cytoplasm was denser and deeper in color, mitochondrion increased in number and became slightly larger than those in the unaffected ones (Supplementary Fig. 1B). In the early stage of injury, starch granules expanded and extruded from the granal lamellae to the edge of chloroplast. The inner side of cell 
wall was deposited with a thin, electron-dense substance that was closely connected to the inside of the cell wall, and the vacuole was muddy and dispersed with a flocculent substance. Finally, the organelles disintegrated and many infected cells collapsed and were filled with a compacted layer of amorphous, moderately electron-opaque material (Supplementary Fig. 1D).

\section{Role of Endogenous Hormones in Gall Formation}

To better understand A. phloeocoptes infestation, hormone content (ZT, IAA, ABA, and GA3) were quantified at different stages of infestation. Maximum ZT content was observed during june and may in healthy and gall buds respectively (Fig. 6A). It is well known that ZT promotes cell division [35]. Therefore, the accumulation of large amounts of ZT led to the rapid bud proliferation during rapid growth period, indicating that within the period from May 30th to June 30th, there was increased vegetative growth in gall buds, which is the initial stage of gall formation.

Similarly, levels of IAA had the same trend like ZT, maximum IAA was observed during June and May in healthy and gall buds respectively (Fig. 6B). We found that IAA level from gallbuds was far lower than that from healthy buds, indicating that a decrease in IAA from gall buds did not result in normal growth. Consequently, young leaves from affected buds were smaller than those from healthy buds.

The levels of ABA from gall buds were significantly higher than healthy buds during the period of study (Fig. 6C). The phytohormone ABA regulates developmental processes and also has a primary function in accelerating aging [36]. Accordingly, the high content of ABA affects the development of apricot buds.

Levels of GA3 were also affected in gall buds compared to healthy buds during the growing season (Fig. 6D). The GA3 content of infested buds had a sharp increase (the increment was 154.6\%) from april to may and reached maximum levels in may, whereas GA3 in healthy buds demonstrated a slow increase (the increment was $37.2 \%$ ) at the same time. GA3 can promote cell elongation and cell division [37]; therefore, gall buds with bigger diameter were formed by the severe distortion and enlargement inside the bud cells. Levels of GA3 in infested buds were much less than those in healthy buds in September, indicating that the lower content of GA3 led to rapid lignification at later stages of the growth.

\section{DISCUSSION}

Apricot bud gall infestation by A. phloeocoptes is complex, not only because of the causal organism but also because the pests are localized in buds and have special dispersal mode. These kinds of eriophyoid mites have a serious impact on the apricot orchard health since it leads a severe deformity of buds and eventually leads to the death of the plant. To understand its life cycle, the regularity in the outbreak, dispersal of A. phloeocoptes, overwintering locations, and mite stages, annual statistics of life stages were analyzed in several orchards. Results suggested that these mites mainly survive over winter in tight, live galls as adults with few eggs. In this study, we observed the passive dispersal modes of $A$. phloeocoptes that were wind, animals and agricultural practices. One of the worth mentioning modes is the animal, which would be far more efficient than any other dispersal modes. Karasawa and Lindo reported a major factor of the colonization of arboreal habitats by oribatid mites which was wind dispersal [38-39] and was partially consistent with our results. 
Ultrastructural studies of pathogens were earlier applied to observe the structure and infection process of rust fungi. Harder [40], Harder \& Chong [41], and Gold \& Mendgen [42] extensively studied the morphology, occurrence and development of rust fungi and its relationship with the host plants through ultrathin sections. However, little was known about the effect of mites on the ultrastructure of the host. Here, we focused the effects of mites on the ultrastructure of host tissues. LanJinghua [43] reported that Tetranychus cinnabar caused partial or complete disappearance of chloroplasts from cotton leaves, disordered arrangement of grana lamellae and increased starch grains. Starch grains are chloroplast photosynthates. When cells are damaged, starch grains cannot be transported to the storage sites normally, which increases their number and accumulation. The starch grains in cotton leaf cells increased significantly after Tetranychus cinnabar infestation [44]. Vacuoles are the largest organelles in plant cells, which are filled with cell fluid to maintain cell morphology and store ions and metabolites. Vacuoles can engulf useless organelles. When cells are damaged, vacuoles rupture and release black osmiophilic substances, which accumulate in cells. In addition, rapid nuclear degradation is triggered by vacuole rupture [45]. Our study demonstrates that cytoplasm of each infected cell was completely disrupted, with severely deformed chloroplasts, mitochondria and irregular vacuoles of an infested bud during later stages of infestation by A. phloeocoptes.

Phytohormones have been speculated to play a vital role in symptom development, yet their precise role was not known. In the previous decade, a large number of studies were carried out to understand the role of phytohormones in plant growth, development, and tolerance against various biotic and abiotic stress [46]. however, it was reported that phytohormones play a key role in the successful infection by affecting insect behavior. Nematode-induced feeding sites show dramatic changes in host cell morphology and gene expression. These changes are likely mediated, at least in part, by phytohormones [47]. Here, we showed that phytohormones played a vital role in the mechanism of gall formation. Accumulation of large amounts of ZT and IAA leads to rapid bud proliferation during rapid growth period. ABA controls bud development and results in quick maturation [48]. Lower levels of GA3 leads to quick lignification at later phases of development [49]. Infection results in 2-4 times less accumulation of IAA and 2.5-5 times more accumulation of GA3 in infected tissue compared to healthy tissues. The difference in hormone content suggests their role in infection and symptom development [50].

\section{Acknowledgements}

This research was supported in part by the National Key R\&D Program of China (project 2016YFD0201100), and by the Modern Fruit Industry Technology System of Gansu Province (GARS-SG-2). We thank Professor Meiliang Zhou for advice and his critical reviews of this manuscript; thank Professor Panos for his critical editing suggestions of the English language; thank Jerry for advice in the statistical analyses and his critical reviews about manuscript. This study was supported by the College of Plant Protection, Gansu Agriculture University, China.

Author Contributions: BingliangXu conceived the study. Shijuan Li, Jin Zhang and Junsheng Yao performed the experiments. Shijuan Li, Muhammad Khurshid, Mohammed Mujitaba Dawuda wrote the manuscript, Zeeshan Hassan and Shahbaz Ahmad provided critical analysis of the design and data.

Competing Interests: The authors declare that they have no competing interests. 
Data and Materials Availability: All data needed to evaluate the conclusions in the paper are present in the paper and/or the Supplementary Materials. Additional data related to this paper may be requested from the authors.

\section{Literature Cited}

1. Castagnoli M.; Oldfield G N. Damage and control of eriophyoid mites in crop: Other fruit trees and nut trees. Amsterdam: Elsevier Science Publishers, 1996, 543-546.

2. Nalepa, A. Zursystematik der gakkmilben. Sitzungsberichte, 1890, 99: 40-69.

3. Wei, Y.L.; X. R. Chen.; S. J. Lin. Occurrence and Control of Apricot Bud Gall. Journal of Gansu Agricultural University, 1991, 3: 66-74.

4. Haiyuan Kuang. Economic Insect Fauna of China. Acari: Eriophyoidea( I )[M], Science Press, China, 1995.

5. WANG, Cheng-xin.; Zhi-long LI.; Mu-zi GUO. Research on Integrated Control Techniques of Bud Gall of Apricot [J]. Journal of Gansu Forestry Science and Technology, 20082.

6. Jin Z.; Bing-liang X U.; Bu-mei W U. Effect of Acalitus phloeocoptes Injury on Morphology and Physiology of Apricot Bud[J]. Acta Horticulturae Sinica, 2014, 41(4): 653.

7. Van Leeuwen, T.; Witters, J.; Nauen, R.; Duso, C.; Tirry, L. The control of eriophyoid mites: state of the art and future challenges. Experimental and Applied Acarology. 2010, doi: 10. 1007 / s 10493 - 009 $9312-9$.

8. WU, B. M.; ZHANG, W. L.; WANG, Y. Q.; \& ZHANG, J. Occurrence and Control Countermeasures of Apricot Bud Gall of Qingwangchuan. Journal of Gansu Forestry Science and Technology, 2011, 02.

9. De Lillo, E. Monfreda. Salivary secretions of eriophyoids (Acari: Eriophyoidea): first results of an experimental model. Experimental and Applied Acarology. 2004, 34: 291-306.

10. Larson, K.C. The impact of two gall-forming arthropods on the photosynthetic rates of their hosts. Oecologia. 1998, 115: 161-166.

11. Petanovic.; R. and Kielkiewicz, M. Plant-eriophyoid interactions: cellular biochemistry and metabolic responses induced in mite injured plants. Experimental and Applied Acarology. 2010, 51: 61-80.

12. Michalska K.; Skoracka, A.; Navia, D.; Amrine, J.W. Behavioural studies on eriophyoid mites: an overview. Experimental and Applied Acarology. 2010, 51:31-59.

13. De Lillo, E.; Skoracka. What's 'cool' on eriophyoid mites. Experimental and Applied Acarology. 2010, 51: $3-30$. 
14. Oldfield, G.N. Biology of gall-inducing Acarina. Biology, ecology and evolution of gall-inducing arthropods. Science Publishers, Inc, Portland. 2005, pp 35-57.

15. Alan HR. Poplar bud gall mite. Insect Diag. 2002, 95:1-3.

16. Ozman, S.K.; Goolsby, J.A. Biology and phenology of the eriophyoid mite, Floracarusperrepae, on its native host in Australia, old world climbing fern, Lygodium microphyllum [J]. Experimental and Applied Acarology. 2005, 35(3):197-213.

17. Xuehui Su., Qingyang Dai. Ultrastructural Changes in Mulberry Leaves Endangered by Eotetranychus suginamensis. Journal of China West Normal University (Natural Sciences). 2002, 23 (3) 265-267.

18. Hori, K. Insect secretions and their effect on plant growth, with special reference to hemipterans. In: Shorthouse, J.D, Rohfritsch, O (eds). Biology of insect-induced galls. Oxford University Press, New York. 1992, Pp: 157-170.

19. Dorchin, N.; Freidberg, A. \& Aloni, R. Morphogenesis of stem gall tissues induced by larvae of two cecidomyiid species (Diptera: Cecidomyiidae) on Suaeda monoica (Chenopodiaceae). Canadian Journal of Botany, 2002, 80, $1141-1150$.

20. Dorchin N.; Hoffman, J.H.; StirkWA.; Novak, O.; Strnad, M.; Van Staden, J. Sexually dimorphic gall structures correspond to differential phytohormone contents in male and female wasps. Physiol Entomol. 2009, 34:359-369.

21. Byers JA., Brewer JW., Denna DW. Plant growth hormones in pinyon insect galls. Marcellia. 39:125134 (1976).

22. Raman, A. Morphogenesis of insect-induced plant galls: facts and questions. Flora-Morphology, Distribution, Functional Ecology of Plants. 2011, 206: 517-533.

23. Kniazev, S. D.; and T. P. Ogolcova. Inheritance of resistance to gall mite evaluation of different cross combination. Modern Black Currant Breeding. 2004, Oriol GAU: 93-100 (in Russian).

24. Brennan, R.; L. Jorgensen.; S. Gordon.; K. Loades.; C. Hackett.; and J. Russell. The development of a PCR-based marker linked to resistance to the blackcurrant gall mite (Cecidophyopsis ribis Acari: Eriophyidae). Theor. Appl. Genet. 2009, 118: 205-211.

25. Stone, G. N. and Schonrogge, K. The adaptive significance of insect gall morphology. Trends in Ecology and Evolution. 2003, 18: 512-522.

26. Zhengli Li. Plant Tissue Sectioning. [M]. Peking University Press, 1996.

27. ZhexinLi.Cytological study of gibberellln regulated xylem development intobacco.Beijing Forestry University, 2014. 
28. Dragana, R.; Branka, S.; Radmila, P.; Biljana, M. Ivotosevsk and Andre G. Anatomical injury induced by the eriophyid mite. Aceriaanthocoptes on the leaves of Cirsiumarvense. Experimental and Applied Acarology. 2006, 38: 243-253.

29. Yanfang Zhang. Study on Morphology and Aatomy of Astragalus membranaceus Roots Infected by the root rot disease. (D) Northwest Normal University, 2013.

30. Jianrong Wu., Lu Mei., Liu tingting. Study on observation of the mycorrhiza under optical and electronic microscope of six orchids. Journal of northwest agricultural and Forestry University of science and Technology (NATURAL SCIENCE EDITION). 2009, 37(7), 199-207.

31. Yang jie.; Zhang riqing.; Jin xiao ling. Application of high performance liquid chromatography to determining endogenous hormones in woody plants. Nonwood Forest Research. 2010, 28 (1): 122-126.

32. Yang TuXi.; Wei AnZhi*; ZhengYuan.; YangHeng.; YangXiang Na.; Zhang Rui. Simultaneous Determination of 8 Endogenous Hormones in Apricot Floral Bud by High Performance Liquid Chromatography. Chinese Journal of Analytical Chemistry. 2007, 35 (9): 1359-1361.

33. Jing huang.; Liu yanzhi.; Liu guowei.; Zhang longping. Research progress in the determination of plant endogenous hormones by high performance liquid chromatography. Shandong Agricultural Sciences [J]. 2011, 101-103.

34. Wu Bumei.; Zhang Wenli.; Wang Youqi.; Zhang jing. Occurrence and Control Countermeasures of Apricot Bud Gall of Qingwangchuan. Journal of Gansu Forestry Science and Tech. 2011, 36 (2): 40-43.

35. ZixinYe. Plant hormones and chemical control of vegetables. [M]. China Agricultural Science and Technology Press. 1988, 11-13.

36. Dapeng Zhang.; Xu Xuefeng.; Zhang Zilian.; Jia Wensuo. Studies on the Veraison Mechanisms: Physiological and Biochemical Responses of Grape Berries to Exogenous Hormone Treatment and Girdling during the Lag Phase of Berry Growth. Acta Horticulturae Sinica. 1997, 24 (1): 1-7.

37. HeitefussR.; WilliamsPH.; Translated by song zuoheng, Zhu younail, Fu Shuyun, etal. Plant pathophysiology. Beijing: Agricultural Press. 1991, 668-672 (1991).

38. Karasawa, S.; Gotoh, K., Sasaki, T.; Hijii, N. Wind-based dispersal of oribatid mites (Acari: Oribatida) in a subtropical forest in Japan. J. Acarol. Soc. Jpn. 2005, 14, 117-122.

39. Lindo, Z.; Winchester, N.N. Scale dependent diversity patterns in arboreal and terrestrial oribatid mite (Acari: Oribatida) communities. 2008, Ecography 31, 53-60.

40. Harder DE. Developmental ultrastructure of hyphae and pore. A. In The Cereal Rust. C. New York: Academic press. 1984, 333-373. 
41. Harder DE, Chong J. Structure and physiology of haustoria. A. In: The Cereal Rust. C. New York: Academic press. 1984, 431-476.

42. Gold RE, Mendgen K. Cytology of teliospore germination and basidiospore formation in Uromyces appendiculatus var. appendiculatus [J]. Protoplasma. 1984, 119:150-155.

43. Lanjinghua. Ultrastructural changes in cotton leaves affected by Carmine spider mite. Journal of Southwest Agricultural University. 1992, 14: 528-530.

44. Petit PX.; Lecoeur H, et a1. Alterations in mitochondrial structure and function are early events of dexamethasone-induced thymocyte apoptosis[J]. J Cell Biol, 1995, 130 (1):157-167.

45. Keisuke Obara.; Hideo Kuriyama.; Hiroo Fukuda. Direct evidence of active and rapid nuclear degradation triggered by vacuole rupture during programmed cell death in zinnia[J]. Plant Physiol. 2001,125(2): 615626.

46. Shabir H.; Wani Vinay Kumar.; Varsha Shriram.; Saroj Kumar Sah. Phytohormones and their metabolic engineering for abiotic stress tolerance in crop plants. The Crop Journal. 2016, 162-176.

47. Gutierrez, O.A.; Wubben, M.J.; Howard, M.; Roberts, B.; Hanlon, E.; Wilkerson, J.R. The role of phytohormones ethylene and auxin in plant-nematode interactions. Russ J Plant Physiol. 2009, 56:1-5.

48. BeruterJ. Effect of abscisic acid on sorbitol uptake in growing apple Fruits. Journal of Experimental Bontany. 1983, 34:737-743.

49. Zhexin Li. Cytological study of gibberellin regulated xylem development in tobacco. Beijing Forestry University , 2014.

50. Palmer A. G.; R. Gao.; J. Maresh.; W. K. Eribil.; D. G. Lynn. Chemical biology of multihost/pathogen interaction: chemical perception and metabolic complementation. Annu. Rev Phytopathol; 2004, 42: 439464. 
Fig. 1 Apricot Bud Gall Symptoms. Apricot tree infested by Acalitus phloeocoptes (Nalepa), (A) different size of galls formed in branches. (B) Galls on one-two year old apricot branches, the galls diameter were1-4 cm. (C) An enlarged apricot bud gall on a severely damaged apricot branch formed by more than 20 buds. (D) A branch with healthy buds.

Fig. 2 Body View of an Adult Female and Egg, (A) Female adult of Acalitus phloeocoptes (Nalepa), The body is vermiform and milky white in color. The adult female is $48.26 \mu \mathrm{m}$ long and $33.63 \mu \mathrm{m}$ wide. (B) Head of the mite, Below the foot base is external genitalia. There are grain dots on genital cover flap. (C) Isosceles triangle shaped dorsal shield of the mite, smooth and without anterior lobe, and has two pairs of legs. (D) Feather claw of the mite. The claws are feathery and have five lateral branches. (E) Lateral microtubercles of the mite. (F) Egg are oval shaped and white in color.

Fig. 3 Passive Spread of $A$. phloeocoptes. (A) The apricot bud gall is surrounded by a necklace like scale insect shell. (B) Nymphs of Pseudaulacaspis pentagona in the scale layers of apricot bud gall. (C) Chilocorus rubidus adults lived on the back of apricot leaves. (D) Adult and nymph of C. rubidus. (E) Nymph of C.rubidus close to apricot bud gall (F) A. phloeocoptes eggs on C.rubidus nymph.

Fig. 4 Deformation Process of an Apricot Acanthoid Gall. (A) Initial stage of apricot bud gall and bud primordium. The bud primordium increased significantly at the axil of young leaves. (B) Mid-stage of apricot bud gall and bud primordium. (C) Late stage of apricot bud gall and bud primordium. Multiple bud cluster structure were formed. D healthy apricot bud. No lignification was observed in the whole bud. Inner leaf, outer leaf, and bud axis were represented by il, ol, and ba respectively.

Fig. 5 Ultrastructure of Apricot Bud Gall Bud Axis Cells. (A) Healthy cell. (B) Early stage of injury period: the starch granules in the axon of the injured bud were obviously expanded, there is a large liquid bubble and a few small vacuoles in the cell, the cell fluid is clear. C: Mid stage of injury: Many vacuoles in the cell are distributed on the edge of the cell. Some vacuoles contain cytoplasmic content, and the cytoplasm seems to be engulfed by vacuoles. (D) Late stage of injury: The nucleus, chloroplast and mitochondrion were seriously deformed, protoplasm became concentrated, and there was no obvious organelle in the cell, but filled with round or irregular vacuoles.

CH: chloroplast; CY: cytoplasm; CW: cell wall; $\mathbf{M}$ : mitochondrion; N: nucleus; $\mathbf{S}$ : starch; V: vacuole; Ve: vesicle; *:electrondense granules 
Fig. 6 Effects of A. phloeocoptes On Phytohormones Content in Apricot Bud Gall. (A) ZT contents quantified during May and October in healthy and gall buds. (B) IAA content quantified during June and May in healthy and gall buds. (C) The ABA content of healthy and gall buds. ABA content was significantly higher than healthy buds during the period of study. (D) The GA content of healthy and gall bud. Infested buds showed a sharp increase of GA content from April to May and reached maximum levels in May, while GA in healthy buds demonstrated a slow increase at the same time.

Table 1. Annual statistic of life stages.

\begin{tabular}{|c|c|c|c|c|c|c|c|c|c|c|c|c|}
\hline Month & 1 & 2 & 3 & 4 & 5 & 6 & 7 & 8 & 9 & 10 & 11 & 12 \\
\hline Egg & 4.92 & 5.54 & 5.16 & 5.09 & 11.92 & 7.15 & 6.03 & 6.85 & 5.40 & 6.32 & 6.31 & 5.35 \\
\hline Nymph & 11.36 & 12.04 & 14.36 & 14.30 & 18.80 & 25.70 & 16.67 & 18.66 & 18.46 & 17.73 & 15.82 & 13.33 \\
\hline Adult & 37.00 & 39.74 & 33.76 & 38.02 & 42.85 & 46.18 & 63.06 & 44.77 & 48.73 & 41.19 & 35.63 & 43.74 \\
\hline
\end{tabular}

Supplementary Fig. 1 Ultrastructure of Apricot Bud Gall Immature Leaf Cells. (A) Early stage of injury: the cell wall of young leaves was obviously thickened, a small amount of starch granules were formed, and the cell fluid in vacuole was clear and bright. Mid stage of injury: (B) Mitochondria are obviously expanded and irregular in shape (C) on the inner side of the cell wall there is a thin layer of electron dense material deposition, which is closely connected with the inner side of the cell wall. (D) Late stage of injury: The organelles in the cells disintegrated, and the substances with high electron density scattered in the cells.

$\mathbf{C H}$ : chloroplast; $\mathbf{C Y}$ : cytoplasm; CW: cell wall; $\mathbf{M}$ : mitochondrion; $\mathbf{N}$ : nucleus; $\mathbf{S}$ : starch; V: vacuole;

Ve: vesicle; *:electron-dense granules.

Supplementary Table 1. Grading standard of apricot bud galls

Supplementary Table 2. Number of Acalitus phloeocoptes (Nalepa) in different stages. Measured from various overwintering places in three consecutive years in Lanzhou City, Gansu Province, China

Number of Acalitus phloeocoptes (Nalepa) of a given stage represents the average across the 3 years of study.

Supplementary Table 3. Differences between infested bud and healthy bud

Means in columns followed by different letters indicate significant difference $(\mathrm{p}<0.01)$. 


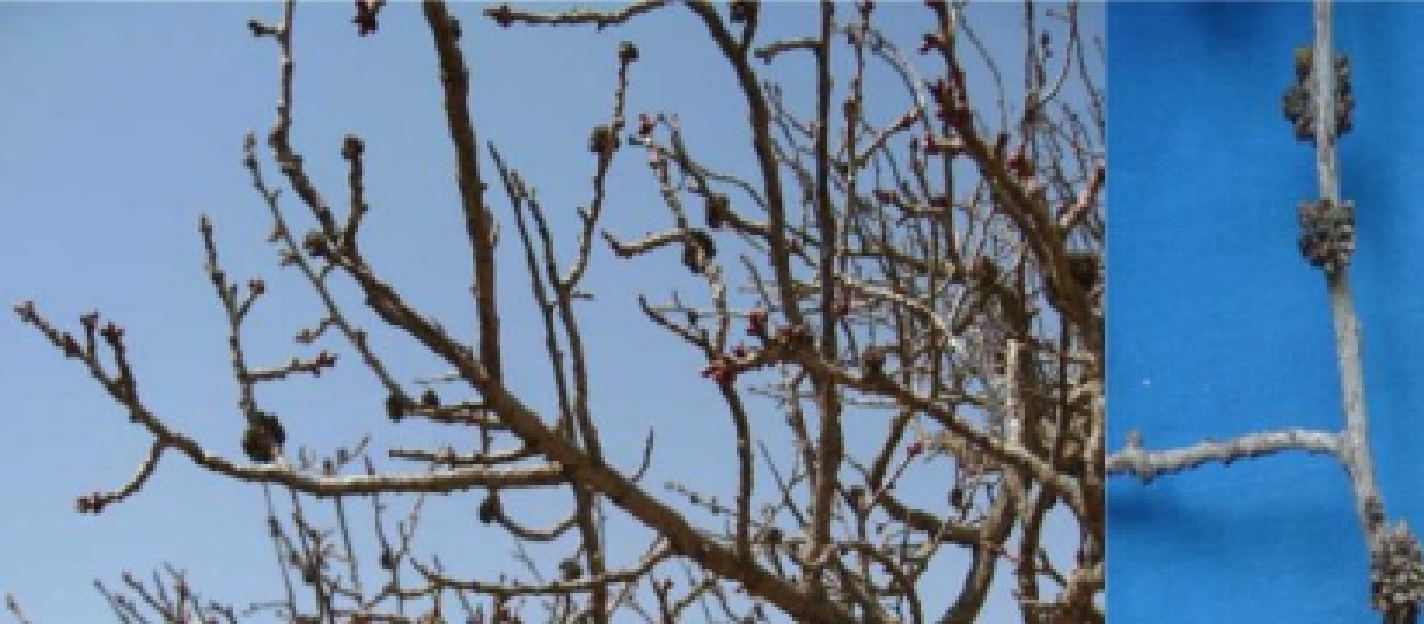

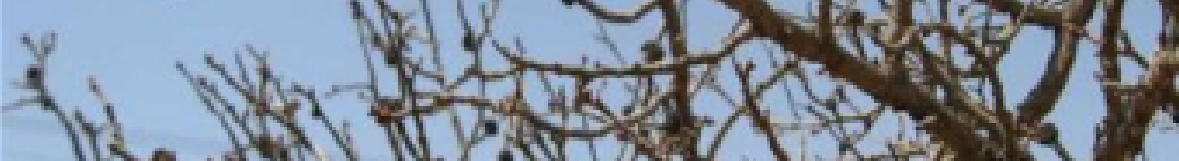
$12+2 \times$ $2+162^{2}$ 1.

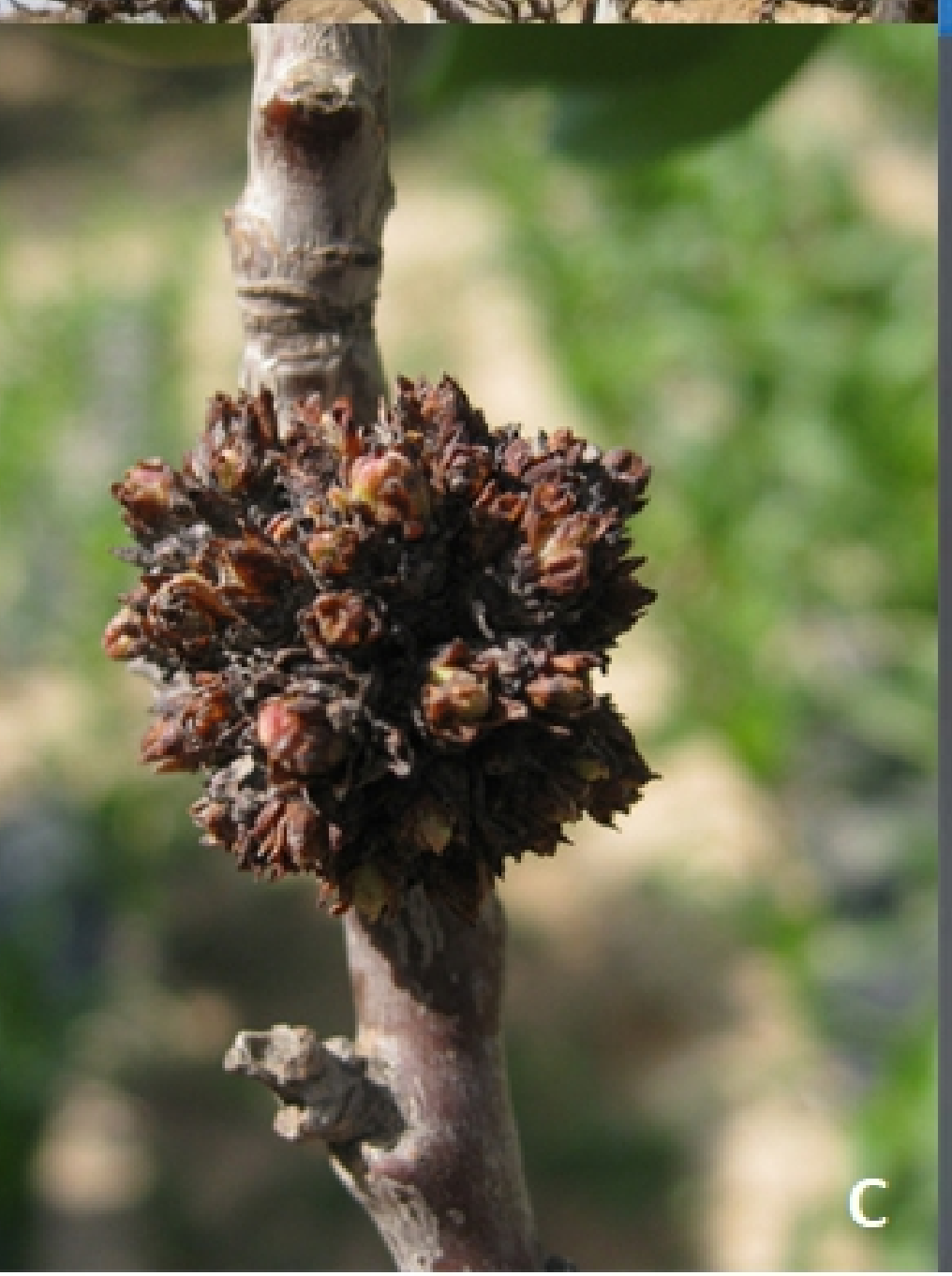

\section{Figure}



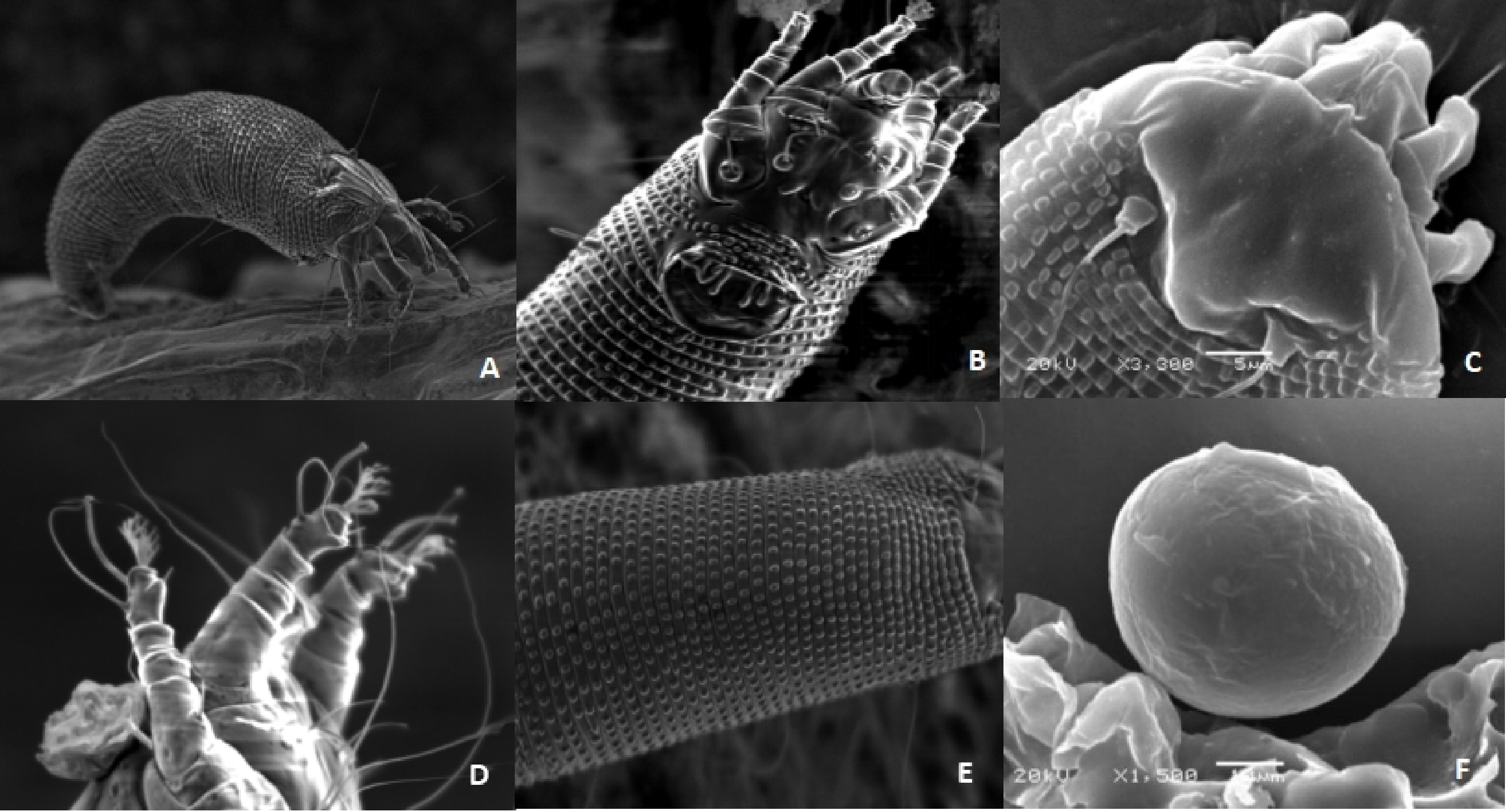

\section{Figure}



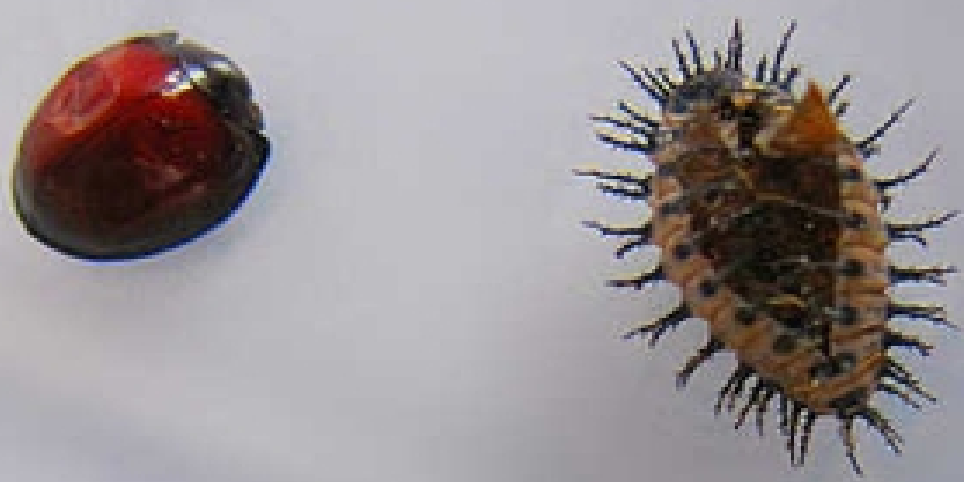

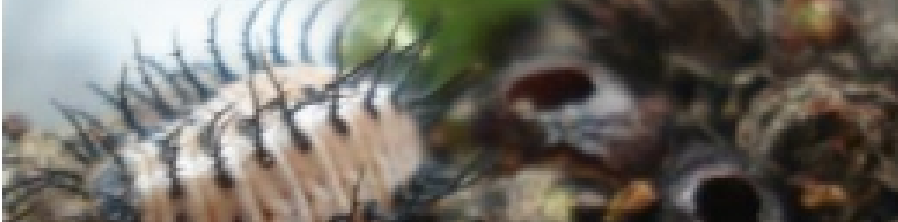
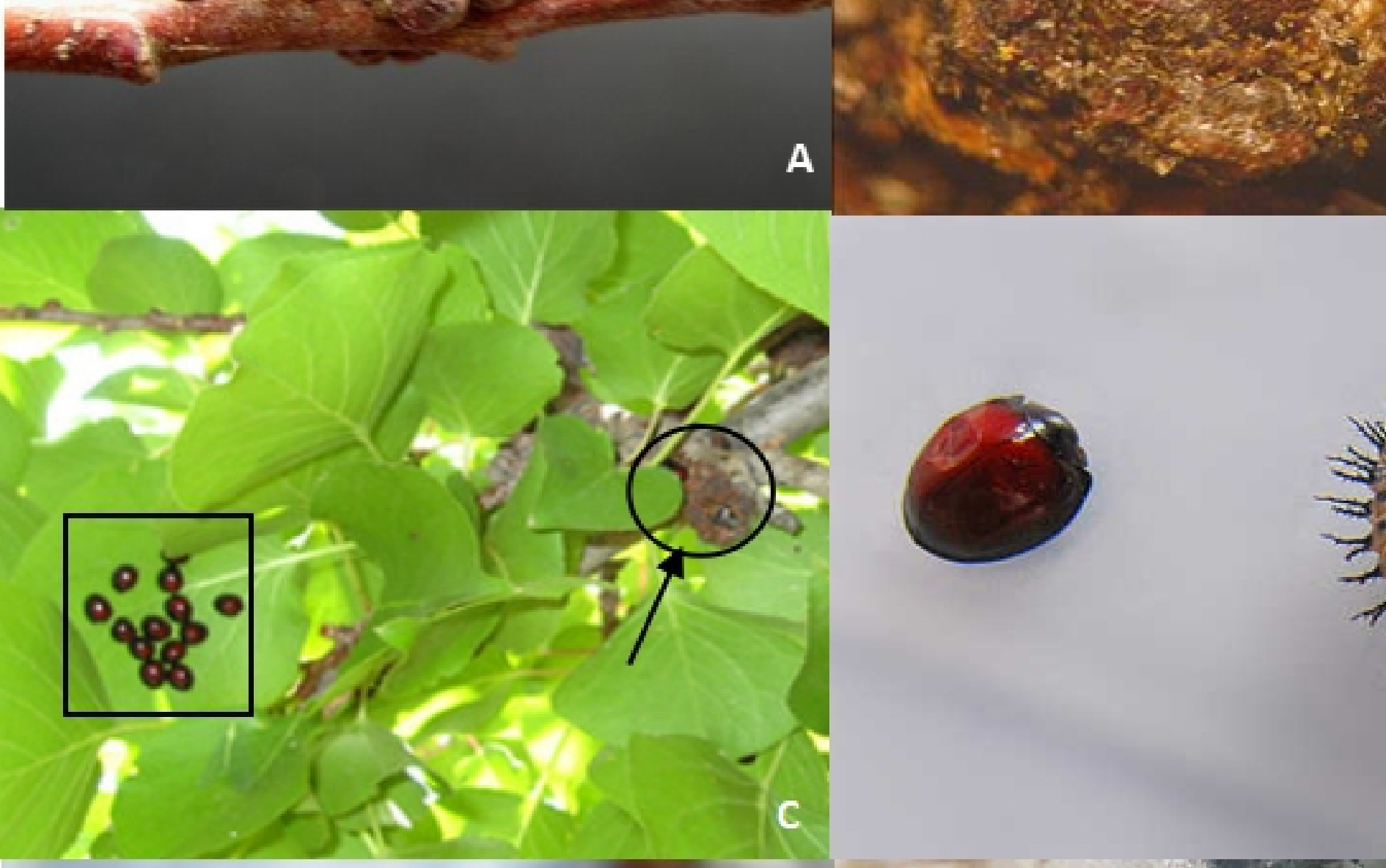

2.45
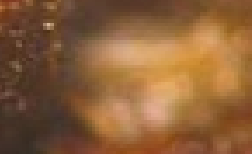

B

D

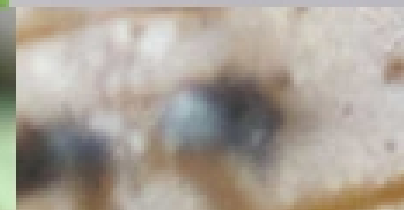




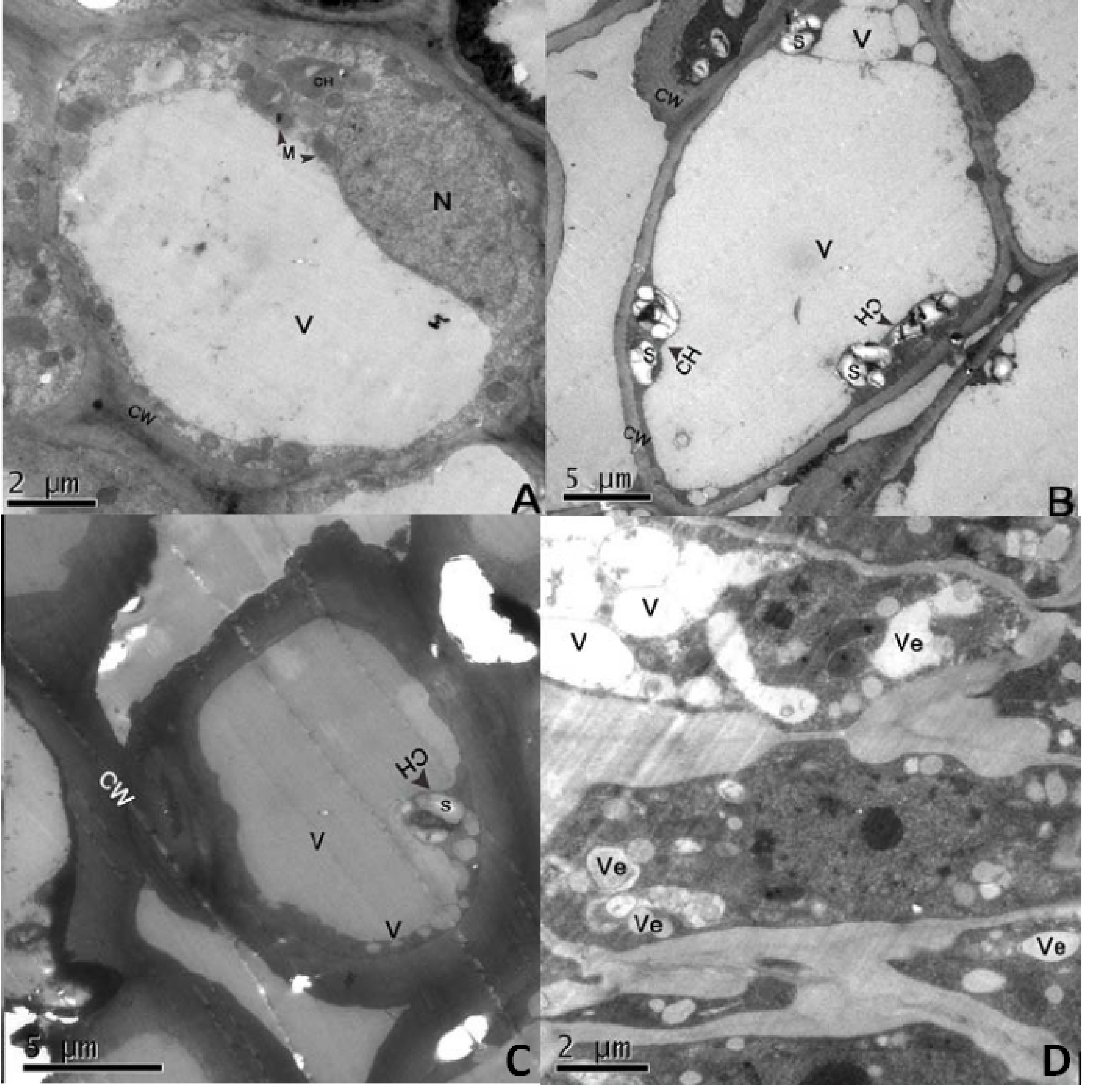

Figure 

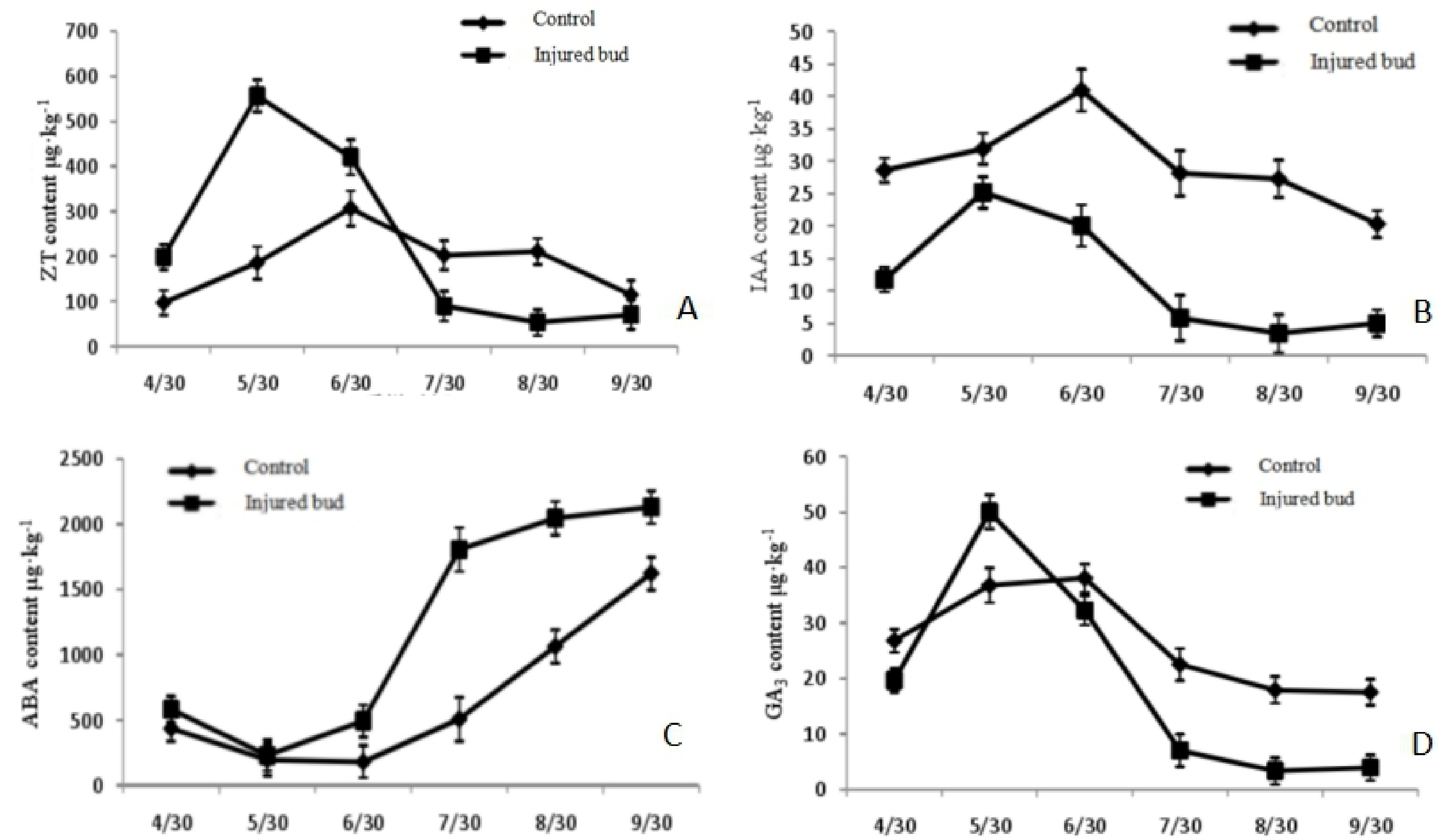

Figure 